\title{
Study of Phenytoin Effect on the genes involved in glucose and lipid metabolism expression in liver: A mouse model study
}

Fatemeh Samimi ${ }^{1}$, Ali Mohammad Ahadi2,", Nafiseh Boroomand ${ }^{2}$, Farzaneh Mohamadzadeh Rostami3

${ }^{1}$ Biochemistry Laboratory, AlZahra Hospital, Isfahan University of Medical Sciences, Isfahan, Iran

${ }^{2}$ Department of Genetics, Faculty of Science, Shahrekord University, Shahrekord, Iran

3Department of Bacteriology and Virology, Faculty of Medicine, Isfahan University of Medical Sciences, Isfahan, Iran

\begin{abstract}
Phenytoin as an anti-seizure medication, is useful for the prevention of tonic-clonic seizures and focal seizures. In this study we focused on the probable effects of Phenytoin drug on gene expression profile of liver related to lipid metabolism balance in mouse as a model. In this study, a group including 7 male mice of BALB/c were treated with phenytoin $3-5 \mathrm{mg} / \mathrm{kg} /$ day orally and a group including 7 male mice of BALB/c were took standard food. Liver tissue samples were isolated. Total RNA was extracted and cDNA was synthesized. Expression of Akt1, Leptin, Adipoq and GLUT4 genes was measured using Realtime RT-PCR method. Results showed an increase about 15 and 3 fold changes in Akt1 $(\mathrm{P}<0.001)$ and Adipoq $(\mathrm{P}<0.001)$ gene expression respectively in treatment group compare to control mice. Also, we detected decreasing in Leptin and GLUT4 genes expression in the mice treated with phenytoin drug. Several studies indicated that phenytoin can promote hyperglycemia in human and animal. We proposed here that this effects may resulted from an interference between the phenytoin drug and gene expression profile in liver. Decreasing of leptin level here may be a result of glucose level elevation in blood that can induce a satiety situation result in decrease of leptin production. It may that Akt1 gene expression is increased to compensate the low level of GLUT4 protein. We concluded that phenytoin is a relatively high-risk antiepileptic drug for obesity and metabolic syndrome, but more studies are needed.
\end{abstract}

Keyword: Phenytoin, Akt1, Leptin, Adipoq, GLUT4

\section{Introduction}

Side effects of drugs is a prevalent problem between the challenges of clinical medicine. Many of medications are vital to treat diseases, but sometimes they have serious side effects [1]. Phenytoin is one of the most effective drugs in treatment and prevention of acute repetitive seizures [2]. Phenytoin is believed to control the seizures by its effects on the voltage-gated sodium channels. This reduces the activity of brain seizure centers by stabilizing the nerve cell membranes
[3]. This drug blocks theinflow of sodium ions through the membranes of the neurons, thereby limiting neurological impulses [4]. The most common side effects of phenytoin include headache, nausea, fever and enlargement of the gums. Phenytoin consumption may be lead to serious side effects include sleepiness, liver problems and low blood pressure [5].

There are several investigations regarding the effects of phenytoin on the metabolism. Studies have shown that phenytoin induce hyperglycemia and

*Corresponding author:

Ali Mohammad Ahadi, Ph.D

Department of Genetics, Faculty of Science,

Shahrekord University, Shahrekord, Iran

(C) The Author(s) 2021

Tel/Fax: +98 3832324419

Email: Ahadi_al@sku.ac.ir

https://orcid.org/oooo-0001-9580-2740
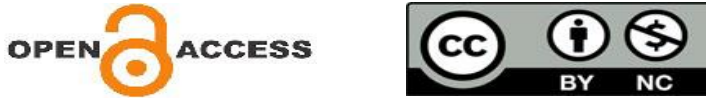

Received: April, 07, 2021

Accepted: May, 15, 2021 
insulin resistance in experimental animal models and human fetus [6, 7]. High levels of blood sugar can lead to complications such as diabetes and metabolic syndrome. Diabetes mellitus is a group of metabolic disorder characterized by chronic hyperglycemia and has a significant impact on the health and quality of life in patients [8]. In the present study, we investigated the effect of phenytoin on mRNA levels of Glut4 (Glucose Transporter 4), Akt1 (protein kinase B), Leptin and Adiponectin (Adipoq) genes in the liver tissue of mouse treated with phenytoin as a models. Insulin is a key factor for managing blood glucose levels by facilitating cellular glucose uptake in several important tissues such as skeletal muscle, liver, and adipose tissue, by activating the PI3K-Akt signaling pathway [9].

GLUT-4 is a protein that plays a crucial role in metabolism of carbohydrates [10]. Glucose uptake in peripheral tissues is mediated by insulin-dependent GLUT4. Insulin stimulate the PI3K-Akt signaling pathway and the activated Akt kinase subsequently catalyzes the phosphorylation of Akt1 substrate 160 $\mathrm{kDa}(\mathrm{AS160})$, responsible for GLUT4 translocation to the plasma membrane and allows glucose uptake to the cells [11]. Akt1 was involved in this study because of its common role in signaling pathways that mediate the metabolic effects of insulin in numerous physiologically important target tissues [12]. Also, one of the most important of hormones in regulation of lipid and glucose level of body is leptin that encoded by LEP gene. Leptin that previously known as obesity factor, is an adipocyte-derived hormone that plays an important role in the regulation of energy stores and food intake [13]. Adiponectin/leptin ratio has been considered as a biomarker for detection of adipose tissue disorders. Leptin is an index of fat mass, and adiponectin is an index for triglyceride metabolism and insulin sensitivity. The people with high adiponectin/leptin ratios have better triglyceride profile [14]. Leptin may have some effects on specific peripheral targets including liver, and pancreas, adipocytes and skeletal muscle cells. Leptin improves hepatic insulin resistance and hyperglycemia through decreasing gluconeogenesis, increases fatty acid oxidation. On the other word, leptin deficiency can lead to insulin resistance diabetes [15]. Leptin can suppresses lipogenesis and glucose output in liver [16]. Adiponectin is another hormone produced by the adipocytes and encoded by Adipoq gene. This gene is down-regulated in obese diabetic patients. Adiponectin enhances insulin secretion to inhibit hepatic glucose production by reducing the gluconeogenic gene expression, so it induces glucose uptake and promotes fatty acid beta oxidation [17]. An optimal level between Leptin and Adiponectin is critical for maintenance of normal metabolism. In leptin-deficient (ob/ob) mice, maintaining adiponectin at lean levels, as opposed to the widely observed drop of adiponectin in the obese state, increases fat mass, yet improves insulin sensitivity [18, 19]. Given to the role of AKt1, Adipoq, LEP and Glut4 genes in regulation of glucose and lipid level of the blood, we think, phenytoin may influence the expression of these genes in the liver. Main goal of this study, was quantitation of the change in expression of these genes after a median term treatment with phenytoin in mouse as an animal model.

\section{Material and Methods}

\subsection{Animals and drug treatment}

Experiments were performed on adult male $\mathrm{BALB} / \mathrm{c}$ mice weighing $24 \pm 3 \mathrm{~g}$. The animals were maintained under controlled room temperature $(25 \pm$ $2^{\circ} \mathrm{C}$ ) and light and dark (12:12 hr) conditions and were given standard food pellets and water. Before conducting the experiment, ethical clearance was obtained from the local Ethical committee on Animal Research and ethical guidelines for investigations were followed in accordance with Shahrekord University guidelines. Experiments consisted of two groups of animals, seven in each group. Group I (standard control), Group II (test drug, intraperitoneal injection, Phenytoin $15-20 \mathrm{mg} / \mathrm{kg}$ ). Before injection, phenytoin was dissolved in distilled water and optimum concentration was calculated. The dose of the drug was calculated according to the manufacturer's recommendation per $\mathrm{kg}$ of body weight for a $25 \mathrm{~g}$ mouse. However, a conversion between mouse and human was carried out [20].

\subsection{Liver tissue biopsy, RNA extraction and cDNA synthesis \\ Mice were anesthetized by intraperitoneal injection (IP) injection of pentobarbital (o.7\%, w/v) and culled by exsanguination. Livers were immediately excised under sterile conditions and directly subjected for total RNA extraction procedures using RNXplus buffer (Cinnagen Co., Iran) as}


recommended by company manual. In the next step, cDNA synthesis was performed on about 5ong RNA by using the first strand cDNA synthesis kit (Add Bio Co., South Korea) using oligo (dT) and random hexamer primers according to the manufacturer's instructions.

\subsection{Primer design and real-time RT-PCR assay}

Specific primers were designed using Generunner version 6.5.52, 64-bit beta software against AKt1, Adipoq, LEP and Glut4 genes that listed in Table 1. Also a pair primers was designed for $A c t B$ gene as internal control or reference gene in relative gene expression analysis in real-time RT-PCR assay. The real-time RT-PCR assay was performed by using the One-step SYBR Green real-time RT-PCR (Takara Bio Inc., Japan). Each $20 \mu L$ reaction mixture contained 10 $\mu \mathrm{L}$ of $2 \mathrm{X}$ Master Mix, $0.5 \mu \mathrm{L}$ of the $20 \mathrm{U} / \mu \mathrm{L}$ RNase inhibitor, $0.8 \mu \mathrm{L}$ each of $10 \mu \mathrm{M}$ forward and reverse primers and $1 \mu \mathrm{L}$ of template cDNA. Amplification was carried out in 48-well plates on a real-time one-step RT-PCR machine (Applied Biosystems Co., USA). Thermal cycling conditions consisted of $10 \mathrm{~min}$ at $95^{\circ} \mathrm{C}$ and 45 cycles of $15 \mathrm{~s}$ at $95^{\circ} \mathrm{C}$ and $1 \mathrm{~min}$ at $60^{\circ} \mathrm{C}$. Melting curve was calculated between $65^{\circ} \mathrm{C}$ and $95^{\circ} \mathrm{C}$ with $0.3^{\circ} \mathrm{C}$ ramping rate.

\subsection{Gene expression and statistical analyses}

Expression changes of studied genes was calculated based on $2^{-\Delta \mathrm{Ct} t}$ method [21]. All results are given as the mean \pm SEM. Kolmograph-Smirnov method was used for normality assay of given data by SPSS version 26. Probabilities of chance differences between two groups were calculated using GraphPad Prism version 9.0.0 with an indipendent t-test method.

\section{Results}

As described in material and method, total RNA was extracted by using RNXplus solution and qualified in gel electrophoresis (Figure 1). The extracted RNA of 28s and 18s rRNA shows an optimal quality.

Supplementary file 1 shows the melt curves for target genes amplicons. The single peak is typically interpreted as representing a pure, single amplicon. Also, amplification plot for every genes is showed.

As mentioned in this study, the expression changes of AdipoQ, Glut4, Leptin and Akt1 genes as candidate genes involved in the metabolism of lipids and carbohydrates under the administration of phenytoin were measured in liver by the $2^{-\Delta \Delta \mathrm{ct}}$ method [18]. The statistical independent t-test method was carried out and the research hypothesis was tested and the results were presented. The distribution of data for

Table 1. Primer sequences for used genes

\begin{tabular}{|c|c|c|c|c|}
\hline Primer name & Sequence & Target length & Target gene & Accession no. \\
\hline mActF & 5'- GGACTCCTATGTGGGTGACG-3' & \multirow{2}{*}{$119 \mathrm{bp}$} & \multirow{2}{*}{$A c t B$} & \multirow{2}{*}{ NM_007393.5 } \\
\hline mActR & 5'- AGGTGTGGTGCCAGATCTTC-3' & & & \\
\hline FAQ1 & 5'-ACTTGTGCAGGTTGGATGG-3' & \multirow{2}{*}{$139 \mathrm{bp}$} & \multirow{2}{*}{$A D I P O Q$} & \multirow{2}{*}{ NM_009605.5 } \\
\hline RAQ1 & 5'-CTGTCTCACCCTTAGGACC-3' & & & \\
\hline FLEP & 5'-CACACACGCAGTCGGTATCC-3' & \multirow{2}{*}{$133 \mathrm{bp}$} & \multirow{2}{*}{ Leptin } & \multirow{2}{*}{ FJ374142.1 } \\
\hline RLEP & 5'-CAGGTCCTCACCAGCCTGCC-3' & & & \\
\hline FGL4 & 5`- AATGTCTTGGCCGTGTTGGG -3` & \multirow{2}{*}{$118 b p$} & \multirow{2}{*}{ GLUT4 } & \multirow{2}{*}{ NM_009204.2 } \\
\hline RGL4 & 5`- GCCCTGATGTTAGCCCTGAG -3’ & & & \\
\hline FAkt1 & 5'-GCCTGAGGAGCGGGAAGAATG-3' & \multirow{2}{*}{$122 \mathrm{bp}$} & \multirow{2}{*}{ Aktl } & \multirow{2}{*}{ NM_001331107 } \\
\hline RAkt1 & 5'-CTTCAGCCCCTGAGTTGTCAC-3' & & & \\
\hline
\end{tabular}


the results of gene expression changes between control group and the animals treated with phenytoin was performed by Kolmograph Smirnov test. Kolmograph Smirnov test showed a significant equal with 0.2 that present normality of data distribution. Based on the result of Kolmograph Smirnov test, independent t-test was considered as significant test for analysis of gene expression change. Figure 2 (A-D) show the result of GLUT4, Leptin, ADIPOQ and Akt1 genes expression analysis. glucose in the hyperglycemic patients that tolerate decrease in adiponectin levels is independent of diabetes type and/or body weight [24]. Adiponectin played a critical role in regulating plasma glucose and reducing pancreatic islet apoptosis after gastric bypass surgery [25]. So, increasing of adiponectin that we reported in this study, may be a secondary or compensation result of hyperglycemia. In this situation, the body may changes its metabolic source from glucose consumption to lipid catabolism.
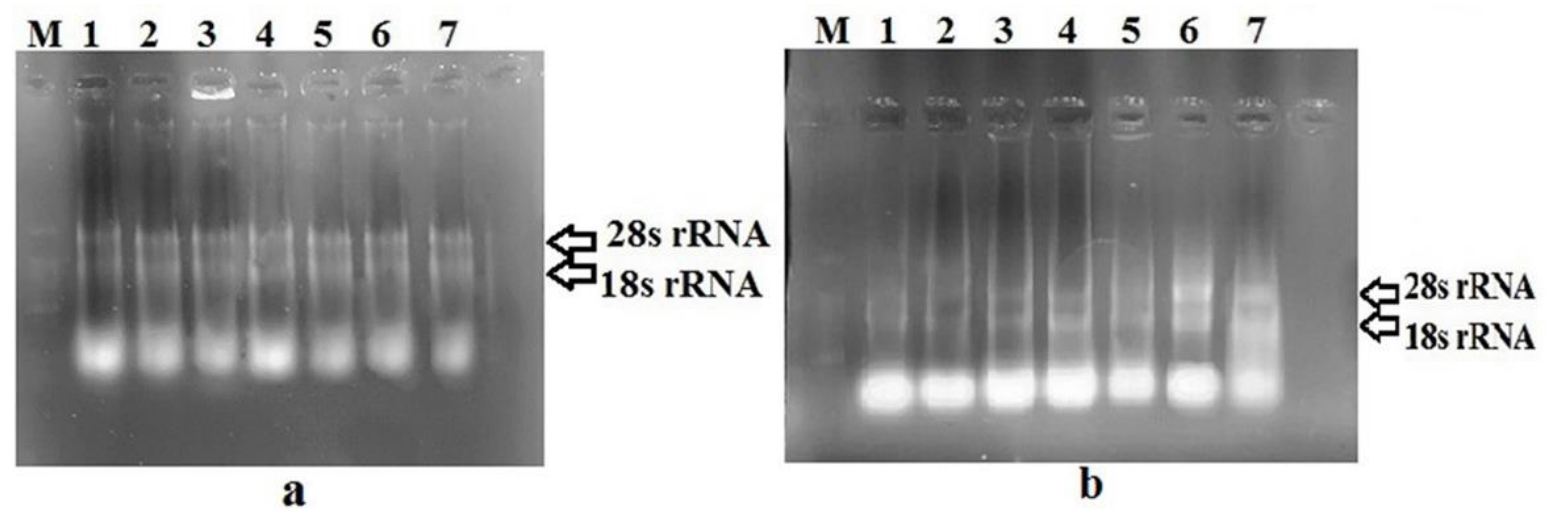

Figure 1. Separation and analysis of RNA. Green viewer-stained 1\% TBE agarose gel showing RNA extracted from liver tissue of treatment (a: 1-7) and control group (b: 1-7) of mice. M: 100bp DNA size marker.

\section{Discussion}

In this study, we investigated the effect of phenytoin drug on the expression of four key genes in metabolism balance of lipids and carbohydrates. Several studies indicated that phenytoin can promote hyperglycemia in human and animal [6, 22, 23]. In a study in the rats, phenytoin significantly increased fasting plasma glucose, insulin resistance index, total cholesterol and triglycerides compared with the control group [6]. This phenomena is very important in about diabetic patients and the peoples that affected by obesity. We proposed here that this effects may resulted from an interference between the phenytoin drug and gene expression profile in liver. As a simple view, adiponectin has been shown to enhance insulin sensitivity in several reports that result in entrance of glucose into the adipocytes and liver cells. In this situation, Leptin hormone acts in reverse direction in releasing of glucose into the blood stream [18]. In our study, Adipoq gene expression showed 15 times increase $(\mathrm{P}<0.001)$ compared to the control group. Adiponectin level elevates with hyperglycemia independent of body size. Optimization of blood
Other result of our study, decreasing of GLUT4 gene expression to 0.4 times $(\mathrm{P}<0.001)$ compare to control group, is compatible with this hypothesis. Also, in this study, we investigated the expression change of Adiponectin and Leptin genes under the phenytoin diet. Adiponectin/Leptin balance is one of the most important indexes for an optimal metabolic condition in the body [26]. Results of this study showed decreasing of Leptin to $0.76(\mathrm{P}<0.05)$ compare to control group. This decreasing of leptin level after the phenytoin consumption, may be a result of glucose level elevation in blood that can induce a satiety situation result in decrease of leptin production.

Similar to our findings, some studies indicated that carbamazepine cause diminish in level of leptin in the patients' blood [27]. Carbamazepine and phenytoin are two common anti-epileptic drug. Decreasing of GLUT4 gene expression that we reported here, must be considered beside of leptin diminish. Low level of leptin in blood can lead to decreasing of insulin secretion and decreased GLUT4 gene expression. Previous researches showed that changes in GLUT4 gene expression under the high 
(a)

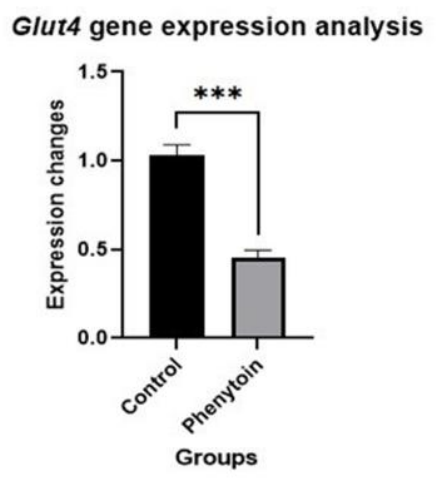

(c)

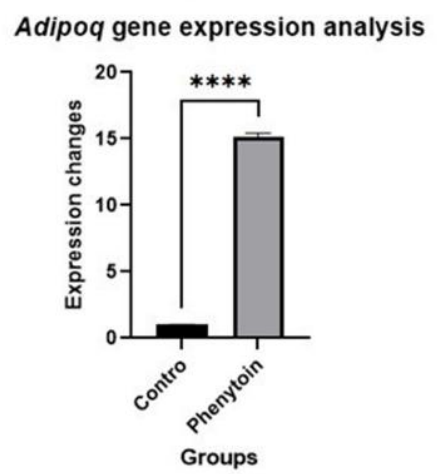

(b)

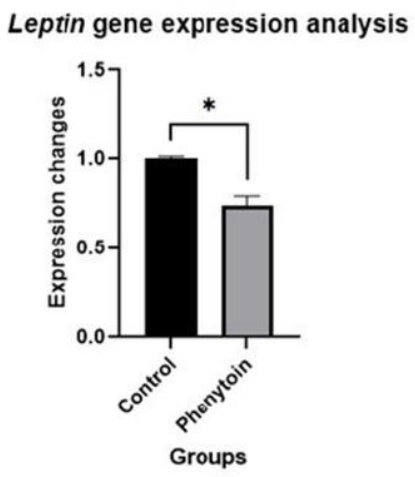

(d)

Akt1 gene expression analysis

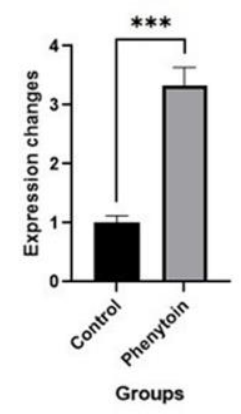

Figure 3. Gene expression changes between control and Phenytoin treated groups. a: GLUT4 gene showed 0.456 decrease in expression compared to the control group $(\mathrm{P} \leq 0.001$, Sig. $=0.00)$. b. Leptin gene expression, which decreased by about $0.76(\mathrm{P} \leq 0.05$, Sig. $=0.01$, Fold change $=0.76152)$ compared to the control group. c: Changes in the expression of Adipoq gene, which is an increase of about 15 times $(\mathrm{P} \leq 0.001$, Sig. $=0.00, \mathrm{FC}=14.78263)$ compared to the control group. d: Aktl gene expression with increase of more than 3 times $(\mathrm{P} \leq 0.001$, Sig. $=0.00, \mathrm{FC}=3.25971)$ compared to the control group.

level of cAMP is accompanied by similar alterations in GLUT4 protein expression and glucose uptake, suggesting a role of GLUT4 gene expression in regulation of cellular insulin role in glucose transport [28]. Based on this findings, we proposed that decreased leptin that resulted from phenytoin drug may be act through a cAMP manner. As supportive reports, correlation analysis indicated that the decrease in GLUT4 gene levels was only observed in hyperglycemic mice. On the other hand, the glucose catabolic related genes do not exhibit any clear coordinate expression. Agitated expression of glucose catabolic genes may contribute to hyperglycemia and muscle insulin resistance [29]. Interestingly, a study showed that hyperglycemia correlate with increasing of GLUT1 protein, while, GLUT4 gene level is decreased under hyperglycemic condition [30]. It seems, because of a wide role of leptin hormone compared with restricted action of adiponectin, the expression changes in leptin gene shows lower variance.

Finally we analyzed the expression of Akt1 gene after treatment of animals with phenytoin drug. Our result showed a more than 3 times increasing in expression for $A k t 1$ gene compare to control group of mice $(\mathrm{P}<0.001)$. Akt1 is expressed in many mammalian tissues. Specially, during adipocyte differentiation in vitro, Akt1 is expressed at a relatively high level in the early stages of adipogenesis, however its expression is gradually decreased at later stages. Thus, it is possible that $A k t 1$ is necessary for the early stages of adipogenesis [31]. Also. Akt1 has a well- 
defined role in phosphorylation and translocation of GLUT4 protein [32, 33]. This role can explains increasing of Akt1 gene expression under phenytoin consumption while GLUT4 gene level has decreased. On the other word, we think that, Akt1 gene expression is increased to compensate the low level of GLUT4 protein. Considering the finding of this study, it can be concluded that phenytoin is a relatively high-risk antiepileptic drug for obesity and metabolic syndrome, but more studies are needed.

\section{Supplementary files}

Supplementary file 1.

\section{Acknowledgements}

We thanks Shahrekord University and Isfahan Medical University for their collaborations.

\section{Author Contributions}

Laboratory work has done by FS. AMA participated as the group leader and the owner of the idea and drafting the manuscript. NB was collaborate as a part of laboratory work and animal treatments. FMR was collaborated writing and editing of manuscript. All authors reads and approved the final version of manuscript.

\section{Conflict of Interests}

The authors declare that they have no competing interests.

\section{Ethical declarations}

The study has been approved by the ethical committee of Shahrekord University. Ethical approval code was IR.SKU.REC.1399.013.

\section{Financial Support}

Not applicable.

\section{References}

1. Webster RK, Rubin GJ. Influencing Side-Effects to Medicinal Treatments: A Systematic Review of Brief Psychological Interventions. Front Psychiatry. 2018; 9:775.

2. Temkin NR, Dikmen SS, Wilensky AJ, Keihm J, Chabal S, Winn HR. A randomized, double-blind study of phenytoin for the prevention of post-traumatic seizures. N Engl J Med. 1990; 323(8):497-502.

3. Molnár P, Erdö SL. Vinpocetine is as potent as phenytoin to block voltage-gated $\mathrm{Na}+$ channels in rat cortical neurons. Eur $\mathrm{J}$ Pharmacol. 1995; 273(3):303-6.
4. Yang M, Kozminski DJ, Wold LA, Modak R, Calhoun JD, Isom LL, et al. Therapeutic potential for phenytoin: targeting Na(v)1.5 sodium channels to reduce migration and invasion in metastatic breast cancer. Breast Cancer Res Treat. 2012; 134(2):603-15. 5. Scheinfeld N. Phenytoin in cutaneous medicine: its uses, mechanisms and side effects. Dermatol Online J. 2003; 9(3):6.

6. Ekaidem IS, Usoh IF, Uboh FE. Phenytoin induced changes in glucose and lipid metabolism is related to increased urate synthesis. J Adv Med Med Res. 2016; 16(7):1-10.

7. Ritchie HE, Oakes D, Farrell E, Ababneh D, Howe A. Fetal hypoxia and hyperglycemia in the formation of phenytoin-induced cleft lip and maxillary hypoplasia. Epilepsia Open. 2019; 4(3):44351.

8. Nair SS, Harikrishnan S, Sarma PS, Thomas SV. Metabolic syndrome in young adults with epilepsy. Seizure. 2016; 37:61-4. 9. Leibiger B, Moede T, Uhles S, Barker CJ, Creveaux M, Domin J, et al. Insulin-feedback via PI3K-C2alpha activated PKBalpha/Akt1 is required for glucose-stimulated insulin secretion. Faseb j. 2010; 24(6):1824-37.

10. Ivy JL. Muscle insulin resistance amended with exercise training: role of GLUT4 expression. Med Sci Sports Exerc. 2004; 36(7):1207-11.

11. Thong FS, Bilan PJ, Klip A. The Rab GTPase-activating protein AS16o integrates Akt, protein kinase C, and AMP-activated protein kinase signals regulating GLUT4 traffic. Diabetes. 2007; 56(2):414-23.

12. Whiteman EL, Cho H, Birnbaum MJ. Role of Akt/protein kinase B in metabolism. Trends Endocrinol Metab. 2002; 13(10):444-51.

13. Perry RJ, Wang Y, Cline GW, Rabin-Court A, Song JD, Dufour S, et al. Leptin Mediates a Glucose-Fatty Acid Cycle to Maintain Glucose Homeostasis in Starvation. Cell. 2018; 172(1-2):23448.e17.

14. Vega GL, Grundy SM. Metabolic risk susceptibility in men is partially related to adiponectin/leptin ratio. J Obes. 2013; 2013:409679.

15. German JP, Wisse BE, Thaler JP, Oh IS, Sarruf DA, Ogimoto K, et al. Leptin deficiency causes insulin resistance induced by uncontrolled diabetes. Diabetes. 2010; 59(7):1626-34.

16. Buettner C, Muse ED, Cheng A, Chen L, Scherer T, Pocai A, et al. Leptin controls adipose tissue lipogenesis via central, STAT3independent mechanisms. Nat Med. 2008; 14(6):667-75.

17. Liu Q, Yuan B, Lo KA, Patterson HC, Sun Y, Lodish HF. Adiponectin regulates expression of hepatic genes critical for glucose and lipid metabolism. Proc Natl Acad Sci U S A. 2012; 109(36):14568-73.

18. Stern JH, Rutkowski JM, Scherer PE. Adiponectin, Leptin, and Fatty Acids in the Maintenance of Metabolic Homeostasis through Adipose Tissue Crosstalk. Cell Metab. 2016; 23(5):770-84.

19. Kim JY, van de Wall E, Laplante M, Azzara A, Trujillo ME, Hofmann SM, et al. Obesity-associated improvements in metabolic profile through expansion of adipose tissue. J Clin Invest. 2007; 117(9):2621-37.

20. Nair AB, Jacob S. A simple practice guide for dose conversion between animals and human. J Basic Clin Pharm. 2016; 7(2):2731.

21. Livak KJ, Schmittgen TD. Analysis of relative gene expression data using real-time quantitative PCR and the 2(-Delta Delta C(T)) Method. Methods. 2001; 25(4):402-8. 


\section{Samimi et al.}

22. Carter BL, Small RE, Mandel MD, Starkman MT. Phenytoininduced hyperglycemia. Am J Hosp Pharm. 1981; 38(10):1508-12. 23. Manto M, Preiser JC, Vincent JL. Hypoglycemia associated with phenytoin intoxication. J Toxicol Clin Toxicol. 1996; 34(2):205-8.

24. Metin Aksu N, Yazgan Aksoy D, Akkaş M, Çinar N, Uçar F, Yildiz OB, et al. Adiponectin levels decrease independently of body mass index and diabetes type after the normalization of hyperglycemia. Turk J Med Sci. 2020; 5O(2):312-5.

25. Chai F, Wang Y, Zhou Y, Liu Y, Geng D, Liu J. Adiponectin downregulates hyperglycemia and reduces pancreatic islet apoptosis after roux-en-y gastric bypass surgery. Obes Surg. 2011; 21(6):768-73.

26. López-Jaramillo P, Gómez-Arbeláez D, López-López J, LópezLópez C, Martínez-Ortega J, Gómez-Rodríguez A, et al. The role of leptin/adiponectin ratio in metabolic syndrome and diabetes. Horm Mol Biol Clin Investig. 2014; 18(1):37-45.

27. Uludag IF, Kulu U, Sener U, Kose S, Zorlu Y. The effect of carbamazepine treatment on serum leptin levels. Epilepsy Res. 2009; 86(1):48-53.

28. Yu ZW, Burén J, Enerbäck S, Nilsson E, Samuelsson L, Eriksson JW. Insulin can enhance GLUT4 gene expression in 3T3-
F442A cells and this effect is mimicked by vanadate but counteracted by cAMP and high glucose--potential implications for insulin resistance. Biochim Biophys Acta. 2001; 1535(2):17485 .

29. Kato M, Suwa A, Shimokawa T. Glucose catabolic gene mRNA levels in skeletal muscle exhibit non-coordinate expression in hyperglycemic mice. Horm Metab Res. 2004; 36(8):513-8.

30. Dimitrakoudis D, Vranic M, Klip A. Effects of hyperglycemia on glucose transporters of the muscle: use of the renal glucose reabsorption inhibitor phlorizin to control glycemia. J Am Soc Nephrol. 1992; 3(5):1078-91.

31. Hay N. Akt isoforms and glucose homeostasis - the leptin connection. Trends Endocrinol Metab. 2011; 22(2):66-73.

32. Hou N, Mai Y, Qiu X, Yuan W, Li Y, Luo C, et al. Carvacrol Attenuates Diabetic Cardiomyopathy by Modulating the $\mathrm{PI}_{3} \mathrm{~K} / \mathrm{AKT} / \mathrm{GLUT} 4$ Pathway in Diabetic Mice. Front Pharmacol. 2019; $10: 998$.

33. Rowland AF, Fazakerley DJ, James DE. Mapping insulin/GLUT4 circuitry. Traffic. 2011; 12(6):672-81. 